\title{
ANALISIS RANTAI NILAI PRODUK OLAHAN TUNA CAKALANG DI PULAU LEMBEH UNTUK PEMASARAN LOKAL DI KOTA BITUNG PROVINSI SULAWESI UTARA
}

\author{
Wandi Rivandi Kharie ${ }^{1}$; Victoria E. N. Manoppo ${ }^{2}$; Martha Wasak ${ }^{2}$ \\ 1) Mahasiswa Fakultas Perikanan dan IImu Kelautan Universitas Sam Ratulangi, Manado. \\ 2) Staff Pengajar Fakultas Perikanan dan IImu Kelautan Universitas Sam Ratulangi, Manado. \\ Koresponden email: marthamasrun@gmail.com
}

\begin{abstract}
Marine fishery production in North Sulawesi is 285265.60 tons in 2015, and special Bitung is 49483.70 tons (Anonimous, 2016). Potential and marine fish production in Bitung is quite high, so the development of the fisheries industry more appropriately directed to marine fisheries processing industry, in particular to increase the added value potential of several types of high economic fish such as tuna and Skipjack (Anwar, 2011)).

The purpose of this research is 1) to analyze how the condition of value chain of processed tuna skipjack products in Lembeh Island for local marketing in Bitung City, North Sulawesi Province. 2 describe any barriers that exist in the processing and marketing of refined product value skipjack tuna in Pulau Lembeh for local marketing in Bitung North Sulawesi. Data analysis was done using descriptive analysis of quantitative and qualitative descriptive.

The results of this study can be concluded, namely:

1. Condition of process value chain of skipjack tuna product on Lembeh Island for local marketing in Bitung City, North Sulawesi Province.

a. The existing value chain from collecting traders to fish processors followed by marketing to coastal community KSU in Sagrat Bitung market.

b. At the fish collecting level are sold in fresh form packed in baskets or buckets / large pans. Sold at Rp. 8.500, - per $\mathrm{kg}$, so the average requirement of $200 \mathrm{~kg}$ per production, then the collecting merchant obtained the proceeds of sales of Rp. 1,700,000, -

c. At the processing level, fish are processed again into processed fish that is $40 \mathrm{~kg}$ of wooden fish and sold for a total price of Rp. 3.600.000, -, the cost of Rp. 220.000, - so get a margin or added value of Rp. 1.680 .000 / production.

d. At the buyer level in this case KSU coastal communities earn margin of Rp.1.550.000, - .

2. Barriers in processing and marketing of skipjack tuna products on Lembeh Island for local marketing in Bitung City of North Sulawesi Province are only at:

a. Still oriented to buyers who are only one person only.

b. Requires more modern equipment to get higher yields.

c. Requires additional capital, in order to diversivikan results of operations.

Departing from obstacles, it can be suggested as follows:

1. Both fishermen, collecting traders, fish processors can increase their production through better and more modern fishing gear

2. Buyers in this case KSU coastal communities can hold additional fish processing as a supplier of wood fish.
\end{abstract}

Keywords: Value Chain, Wooden Fish, Lembeh

\section{Abstrak}

Produksi perikanan laut di Sulawesi Utara 285265.60 ton di tahun 2015, dan khusus Bitung berjumlah 49483.70 ton (Anonimous, 2016). Potensi dan produksi perikanan laut di Kota Bitung cukup tinggi, sehingga pengembangan industri perikanannya lebih tepat diarahkan pada industri pengolahan perikanan laut, khususnya untuk peningkatan nilai tambah potensi beberapa jenis ikan ekonomis tinggi seperti Tuna dan Cakalang (Anwar, 2011)).

Tujuan penelitian ini, yaitu 1) menganalisis bagaimana kondisi rantai nilai produk olahan tuna cakalang di Pulau Lembeh untuk pemasaran lokal di Kota Bitung Provinsi Sulawesi Utara. 2 mendeskripsikan hambatan-hambatan apa saja yang ada dalam proses pengolahan dan pemasaran nilai produk olahan tuna cakalang di Pulau Lembeh untuk pemasaran lokal di Kota Bitung Provinsi Sulawesi Utara. Analisis data dilakukan menggunakan analisis deskriptif kuantitatif dan deskriptif kualitatif.

Hasil penelitian ini dapat disimpulkan, yaitu :

1. Kondisi rantai nilai produk olahan tuna cakalang di Pulau Lembeh untuk pemasaran lokal di Kota Bitung Provinsi Sulawesi Utara.

a. Rantai nilai yang ada mulai dari pedagang pengumpul ke pengolah ikan dilanjutkan dengan pemasaran ke KSU masyarakat pesisir di pasar Sagrat Bitung. 
b. Pada tingkat pengumpul ikan dijual dalam bentuk segar dikemas dalam keranjang atau ember/loyang besar. Dijual dengan harga Rp. 8.500,- per kg, sehingga kebutuhan rata-rata $200 \mathrm{~kg}$ per produksi, maka pedagang pengumpul memperoleh hasil penjualan sebesar Rp. 1.700.000,--

c. Pada tingkat pengolah, ikan diproses lagi menjadi ikan olahan yaitu ikan kayu sebanyak $40 \mathrm{~kg}$ dan dijual dengan harga total Rp. 3.600.000,-, biaya sebesar Rp. 220.000,- sehingga memperoleh margin atau nilai tambah sebesar Rp. 1.680.000/produksi.

d. Di tingkat pembeli dalam hal ini KSU masyarakat pesisir memperoleh margin sebesar Rp.1.550.000,-

2. Hambatan-hambatan dalam proses pengolahan dan pemasaran produk olahan tuna cakalang di Pulau Lembeh untuk pemasaran lokal di Kota Bitung Provinsi Sulawesi Utara hanyalah pada :

a. Masih berorientasi ke pembeli yang hanya satu orang saja.

b. Memerlukan peralatan yang lebih modern untuk mendapatkan hasil produksi lebih tinggi.

c. Memerlukan tambahan modal, agar bisa diversivikasi hasil usaha.

Bertolak dari hambatan, maka dapatlah disarankan sebagai berikut :

1. Baik nelayan, pedagang pengumpul, pengolah ikan bisa meningkatkan produksinya melalui peralatan tangkap yang lebih baik dan lebih modern

2. Pembeli dalam hal ini KSU masyarakat pesisir bisa mengadakan tambahan binaan pengolah ikan sebagai penyedia ikan kayu.

Kata kunci : Rantai Nilai, Ikan Kayu , Lembeh

\section{PENDAHULUAN}

Bitung merupakan salah satu kawasan pengembangan perikanan di Provinsi Sulawesi Utara. Lokasi ini memiliki infrastruktur yang mendukung bongkar muat barang dari desa dan ke Kota Bitung dan Pelabuhan Perikanan Samudra (PPS) Bitung. Potensi dan produksi perikanan laut di Kota Bitung cukup tinggi, sehingga pengembangan industri perikanannya lebih tepat diarahkan pada industri pengolahan perikanan laut, khususnya untuk peningkatan nilai tambah potensi beberapa jenis ikan ekonomis tinggi seperti Tuna dan Cakalang (Anwar, 2011).

Keberlanjutan kegiatan

Perikanan Tuna Cakalang sangat dipengaruhi oleh sistem rantai nilai yang dibangun oleh pelaku usaha Tuna Cakalang mulai dari menangkap ikan di laut, diversifikasi produk oleh pengolah atau industri pengolahan, distribusi produk, serta pemasarannya hingga produk Tuna Cakalang sampai ke tangan konsumen lokal maupun luar negeri.

\section{Rumusan Masalah}

Bertolak dari latar belakang di atas, maka perumusan masalah adalah sebagai berikut:

1. Bagaimana kondisi rantai nilai produk olahan Tuna cakalang di Pulau Lembeh untuk pemasaran lokal di Kota Bitung Provinsi Sulawesi Utara?.

2. Hambatan-hambatan apa saja yang ada dalam proses pengolahan dan pemasaran nilai produk olahan Tuna cakalang di Pulau Lembeh untuk pemasaran lokal di Kota Bitung Provinsi Sulawesi Utara?.

\section{Tujuan dan Manfaat Penelitian Tujuan Penelitian}

1. Untuk menganalisis bagaimana kondisi rantai nilai produk olahan Tuna Cakalang di Pulau Lembeh untuk pemasaran lokal di Kota Bitung Provinsi Sulawesi Utara.

2. Untuk mengdeskripsikan hambatanhambatan apa saja yang ada dalam proses pengolahan dan pemasaran nilai produk olahan tuna cakalang di Pulau Lembeh untuk pemasaran lokal di Kota Bitung Provinsi Sulawesi Utara. 


\section{Manfaat Penelitian}

Memberikan informasi penting bagi pemerintah daerah maupun pemerintah provinsi serta pihak swasta dan masyarakat yang ingin mengembangkan usaha ikan kayu olahan dengan menggunakan bahan baku Tuna dan Cakalang.

\section{Tempat dan Waktu Penelitian}

Penelitian ini dilaksanakan di wilayah pesisir Pulau Lembeh Kota Bitung Provinsi Sulawesi Utara. Waktu yang diperlukan dalam pelaksanakan penelitian selama 4 bulan adalah dimulai dari pra survei lokasi, konsultasi, penyusunan proposal, ujian proposal, pelaksanaan penelitian, pengolahan data dan analisis data serta penyususnan skripsi, seminar hasil dan sampai pada ujian komprehensif.

\section{METODOLOGI PENELITIAN \\ Metode Pengambilan Sampel}

Penelitian ini bersifat survei. Pengambilan sampel dalam penelitian ini digunakan metode purposive sampling. Di Pulau Lembeh terdapat pengolah ikan baik di Lembeh Papusungan, Lembeh Batulubang, Pulau Lembeh Pasir Panjang dan Pulau Lembeh Pintu Kota.

Dalam penelitian ini untuk memperoleh jumlah sampel dipergunakan teori Gay yang menyatakan bahwa ukuran sampel yang dapat diterima yaitu untuk populasi yang jumlahnya relatif kecil, minimal sampel yang diambil adalah sebesar $10 \%$ dari jumlah populasi (Umar, 2000). Populasi atau pengolah di Pulau Lembeh berjumlah 60 orang. Untuk menghemat biaya, tenaga dan waktu hanya diambil sebesar 6 orang yang bertempat tinggal di Papusungan dan Batulubang.

\section{Metode Pengumpulan Data}

Menurut Kuncoro (2003), sumber data terdiri atas data primer dan data sekunder. Kriteria responden yang diwawancarai yakni pelaku pengolah ikan yang bersedia diwawancarai dan memahami permasalahan perikanan secara umum serta diproritaskan pengurus kelompok pengolah ikan dalam hal ini pemilik usaha.

Data tersebut antara lain data mengenai distribusi nilai tambah yang terdapat pada rantai nilai ikan kayu, serta data-data terkait lainnya. Responden dalam penelitian ini adalah ketua kelompok pengolah dan pemilik Koperasi Serba Usaha sebagai informasi kunci. Wawancara juga dilakukan terhadap pihak-pihak lain yang terkait seperti Lurah Papusungan dan Lurah Batulubang dan Kadis Dinas Perikanan Bitung.

\section{Metode Analisis Data}

Analisis data yang digunakan dalam penelitian ini adalah analisis deskriptif kualitatif dan deskriptif kuantitatif. Untuk menganalisis bagaimana kondisi rantai nilai dan mendeskripsikan hambatan-hambatan apa saja yang ada dalam proses pengolahan dan pemasaran produk olahan Tuna Cakalang di Pulau Lembeh untuk pemasaran lokal di Kota Bitung Provinsi Sulawesi Utara menggunakan analisis deskriptif kuantitatif dan deskriptif kualitatif.

\section{HASIL DAN PEMBAHASAN}

\section{Gambaran Umum Pulau Lembeh}

Pulau Lembeh atau Dembet adalah suatu pulau yang terjadi dari batu-batu karang dan terletak pada 
01025,'4 Lintang Utara dan 125013,'5 Bujur Timur dan pada zaman purba atau zaman Neulitikum, di atas sepuluh juta tahun lalu pulau Lembeh menyatu dengan Malesung/Minahasa. Tetapi oleh keadaan gempa bumi dan perkembangannya sejak zaman itu, maka bagian yang menanjung itu teretak pecah lalu terdorong keluar, sehingga selahnya dimasuki air laut dan terjadilah selat. (Lengkong, 1981 dalam Darenoh, 2015).

\section{Profil Pengolah Ikan Kayu Pekerjaan Utama Pengolah}

Secara sederhana dapatlah disampaikan bahwa di Pulau Lembeh kegiatan pengolahan ikan kayu dilaksanakan oleh sebagian besar masyarakat setempat secara tradisional. Ikan cakalang adalah ikan yang sering dipakai sebagai bahan baku utama, namun ada juga ikan tongkol di saat ikan cakalang mahal harganya.

\section{Lokasi Usaha}

Lokasi penelitian yaitu di Pulau Lembeh, menunjukkan bahwa Kelurahan Papusungan dan Kelurahan Batulubang, yaitu sejumlah $33 \%$ merupakan lokasi yang sama banyaknya terdapat pengolah pemilik

\section{Kegiatan Pengolahan Ikan}

Tempat Pengolahan di Lembeh adalah tempat pengolahan yang didirikan sejak 10 tahun yang silam. Nanti pada tahun 2013 berjalan lancar dengan adanya bantuan proyek Dana Internasional untuk Pengembangan Agrikultural atau International Fund for Agricultural Development (IFAD).

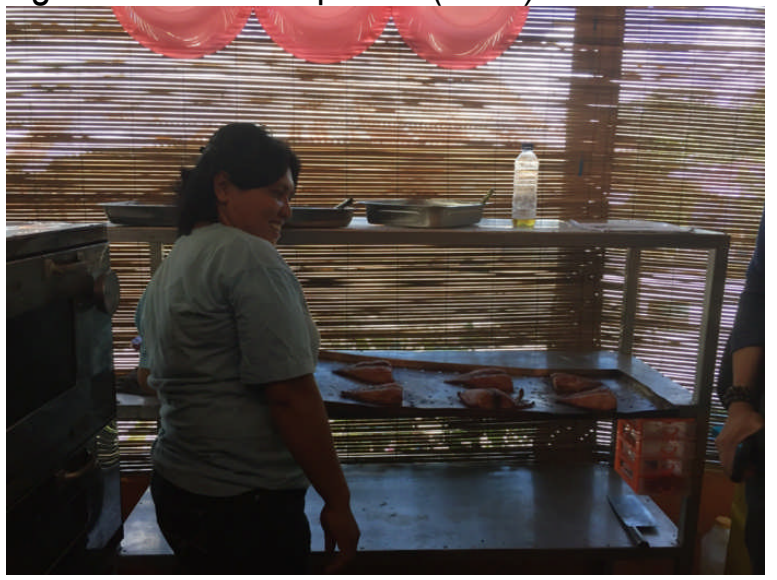

Gambar . Profil Pemilik Pengolahan Ikan Kayu

Gambar di atas menunjukkan bahwa kegiatan pengolahan ikan kayu di Lembeh adalah kegiatan pengolahan secara tradisional. Ikan yang diperoleh dari pedagang pengumpul selanjutnya dicuci dan langsung direbus selama setengah jam. Kemudian diadakan tindakan pemisahan antara tulang dan daging. Setelah semuanya selesai dilanjutkan dengan pengasapan yang berlangsung minimal 4 hari dan maksimal 1 minggu.

Untuk ikan yang berat per ekor di atas 1 kilogram, maka itu yang mengalami proses pengasapan selama 1 minggu karena dagingnya tebal.

Langkah-langkah pengolahan dapat dilihat pada Gambar 2 di bawah ini: 


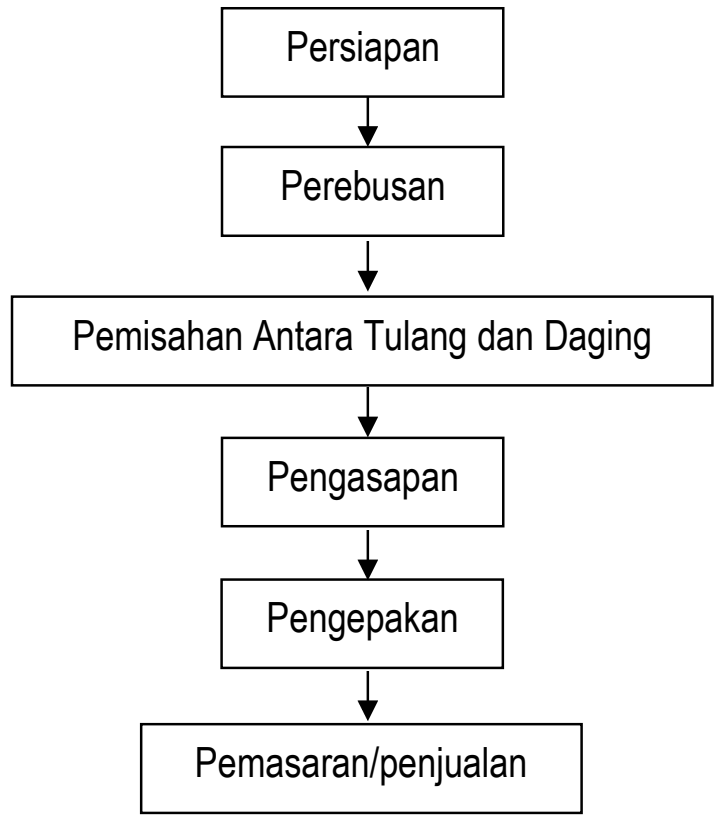

Gambar. Skema langkah-langkah pengolahan ikan kayu di Lembeh

\section{Rantai Pemasaran Ikan Kayu}

Kegiatan pengolahan ikan kayu di Lembeh mulai dari bagaimna cara mereka mendapatkan ikan sampai pada pengolahan dan kemudian dipasarkan.

Rantai pemasaran dapat dilihat pada Gambar berikut ini :
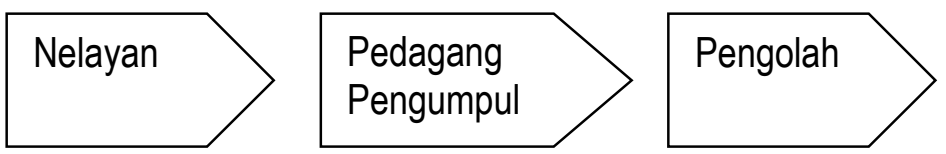

Pembeli/KSU

Masyarakat Pesisir

\section{Gambar . Rantai Pemasaran Ikan Kayu}

Gambar ini menunjukkan bahwa pengolah memperoleh ikan dari Pedagang Pengumpul yang memperoleh ikan dari Nelayan/Tempat Pelelangan Ikan di Aertembaga Bitung. Selanjutnya Pedagang Pengumpul membawa sampai ke Dermaga Papusungan. Selanjutnya ikan tersebut masuk dalam proses pengolahan. Ikan selanjutnya masuk dalam prose pengasapan dan setelah selesai ikan dikemas dalam karung yang sudah disiapkan dan di bawa ke pasar di daerah Sagrat yaitu ke
Koperasi Serba Usaha (KSU) masyarakat pesisir sebagai pemasok/pembeli tunggal. Dalam proses pembelian di Koperasi Serba Usaha (KSU), ikan dibeli dengan melihat kualitas ikan, tetapi apapun kualitas tetap dibayar tunai.

\section{Perhitungan Biaya dan Nilai Tambah} Adapun biaya dan nilai tambah pada setiap rantai kegiatan di masingmasing tingkatan dapat dibaca Tabel berikut ini. 
Tabel. Biaya-Biaya Pada Setiap Rantai Kegiatan

\begin{tabular}{|c|c|c|c|c|}
\hline Uraian & Nelayan & Pedagang Pengumpul & Pengolah ikan & $\begin{array}{l}\text { KSU Masyarakat } \\
\text { Pesisir }\end{array}$ \\
\hline Asal ikan & $\begin{array}{l}\text { Tempat Pelelangan } \\
\text { lkan/Tempat Pendaratan } \\
\text { lkan }\end{array}$ & $\begin{array}{l}\text { Dari Nelayan } \\
200 \text { kg ikan cakalang @ } \\
\text { Rp. 5000,- }\end{array}$ & $\begin{array}{l}\text { Dari pedagang } \\
\text { pengumpul } 200 \mathrm{~kg} \\
\text { ikan cakalang } \\
@ \text { Rp. } 8.500\end{array}$ & \\
\hline $\begin{array}{l}\text { Dijual ke Pedagang } \\
\text { Pengumpul }\end{array}$ & $\begin{array}{l}\text { Rp. } 200 \mathrm{~kg} \times \text { Rp. } 5.000,-= \\
\text { Rp. } 1.000 .000\end{array}$ & & & \\
\hline Bayar ke Nelayan & & Rp. 1.000 .000 & & \\
\hline Ongkos melaut & Rp. 100.000 & & & \\
\hline Penerimaan & Rp.900.000,- & & & \\
\hline $\begin{array}{l}\text { Hasil Penjualan } \\
\text { Ke Pengolah lkan }\end{array}$ & & $\begin{array}{l}200 \text { kg ikan cakalang } \\
@ \text { Rp. 8.500,-= Rp. } \\
1.700 .000,-\end{array}$ & & $40 \mathrm{~kg}$ \\
\hline $\begin{array}{l}\text { Bayar transportasi dari } \\
\text { TPI Aertembga ke } \\
\text { Dermaga Papusungan } \\
\end{array}$ & Rp. 50.000,- & & & \\
\hline $\begin{array}{l}\text { Bayar Tenaga Kerja } 1 \\
\text { orang }\end{array}$ & Rp. 50.000,- & & & \\
\hline Total Pengeluaran & & Rp. 100.000 & & \\
\hline Penerimaan & & $\begin{array}{l}\text { Rp. 1.700.000,- - Rp. } \\
\text { 100.000,- = Rp. } \\
\text { 1.600.000,- }\end{array}$ & & \\
\hline $\begin{array}{l}\text { Bayar ke Pedagang } \\
\text { Pengumpul }\end{array}$ & & & Rp.1.700.000,- & \\
\hline $\begin{array}{l}\text { Dijual ke KSU Masyrakat } \\
\text { Pesisir }\end{array}$ & & & $\begin{array}{l}40 \text { kg ikan kayu } \\
@ 90.000 .000,-R p . \\
3.600 .000,-\end{array}$ & \\
\hline $\begin{array}{l}\text { Ongkos mengangkut dari } \\
\text { dermaga Papusungan ke } \\
\text { lokasi pengolahan }\end{array}$ & & & Rp. 20.000,- & \\
\hline $\begin{array}{l}\text { Biaya tenga kerja } \\
\text { Transportasi ke KSU } \\
\text { Masyarakat Pesisir } \\
\end{array}$ & & & $\begin{array}{l}2 \text { orang } \\
@ \text { Rp 50.000,- } \\
=\text { Rp. } 100.000 \\
\text { Rp. } 100.000,-\end{array}$ & \\
\hline Total Pengeluaran & & & Rp. 1.920.000 & \\
\hline Hasil Bersih & & & $\begin{array}{l}\text { Rp. } 3.600 .000,-- \\
\text { Rp. } 1.920 .000,- \\
=\text { Rp. } 1.680 .000\end{array}$ & \\
\hline Dibeli dari pengolah ikan & & & & $\begin{array}{l}40 \mathrm{~kg} \text { ikan kayu } \\
@ 90.000 .000,-\end{array}$ \\
\hline Bayar ke Pengolah & & & & Rp. 3.600.000,- \\
\hline Penjualan & & & & $\begin{array}{l}40 \mathrm{~kg} \\
@ \text { Rp. } 150.000 .,- \\
=\text { Rp. } 6.000 .000,-\end{array}$ \\
\hline Ongkos Pengiriman*) & & & & $\begin{array}{l}40 \text { kg@ Rp. 25.000.= } \\
\text { Rp. } 800.000,-\end{array}$ \\
\hline Transportasi ke bandara*) & & & & Rp. 50.000 \\
\hline Total Pengeluaran & & & & Rp.4.450.000,- \\
\hline Hasil bersih & & & & $\begin{array}{l}\text { Rp. 6.000.000,-- } \\
\text { Rp.4.650.000,-- } \\
=\text { Rp.1.550.000,- }\end{array}$ \\
\hline
\end{tabular}

Sumber : Hasil Olahan Data Primer, 2017

$=$ Rp.1.550.000,-

Ket. *) Ongkos pengiriman dan transportasi ke bandara dilakukan sekaligus sesuai permintaan pembeli.

Tabel di atas menunjukkan bahwa terjadi perubahan-perubahan nilai dalam hal biaya dan margin. Mulai dari pedagang pengumpul, dijual ke 
pengolah ikan kayu selanjutnya dipasarkan ke KSU Masyrakat Pesisir.

Secara rinci dapat dipelajari pada uraian di bawa ini :

\section{Tingkat Nelayan}

Nelayan memperoleh ikan tangkapan dengan mengeluarkan biaya operasional Rp. 100.000,- / trip. Kemudian mereka menjual sebagian dari hasil tangkapannya kepada pedagang pengumpul sebanyak $200 \mathrm{~kg}$ dengan harga rata-rata Rp. 5000,-/kg. Nelayan memperoleh hasil penjualan sebesar Rp. 1.000.000,- , hasil bersih yang diperoleh nelayan $\mathrm{Rp}$. 900.000,--

\section{Tingkat Pedagang Pengumpul}

Sumber bahan baku untuk usaha ini adalah berasal dari pedagang pengumpul. Untuk jenis ikan cakalang mentah sering atau harga rata-rata dijual dengan harga Rp. 5.000,- per kg, sehingga jika jumlah yang dibeli sebanyak $200 \mathrm{~kg}$ maka harga menjadi Rp. 1.000.000,. Untuk membawa ikan ini dari TPI Aertembaga ke Dermaga Papusungan memerlukan Rp. 50.000 ,- dan ongkos tenaga kerja Rp. 50.000,-. Selanjutnya dibeli oleh pengolah seharga Rp. 8.500,-,/kg, sehingga pedagang pengumpul menerima hasil penjualan Rp. 1.700.000,-. Hasil penjualan ini dikurangi biaya transport dan tenaga kerja, mendapatkan hasil bersih sebanyak Rp. 1.600.000,-.

\section{Tingkat Pengolah}

Ikan yang dibeli terdiri atas ikan tuna dan ikan cakalang, namun sebagian besar pengolahan menggunakan ikan cakalang. Minimal produksi $10 \mathrm{~kg}$ dan maksimal $500 \mathrm{~kg}$. Rata-rata setiap produksi dengan menggunakan ikan cakalang sejumlah $200 \mathrm{~kg}$.

Pengolahan ikan kayu memang membutuhkan perhitungan nilai yang cukup rumit. Hasil penelitian menunjukkan bahwa jika ikan cakalang mentah yang sebanyak $5 \mathrm{~kg}$ hanya menghasilkan $1 \mathrm{~kg}$ ikan kayu sehingga apabila digunakan sebanyak 200 kg (1 ekor dengan berat $1 \mathrm{~kg}+)$ maka rata-rata hanya menghasilkan $40 \mathrm{~kg}$ ikan kayu dan ikan kayu ini dijual dengan harga rata-rata Rp. 90.000,-. Apabila jumlah produksi dengan menggunakan ikan cakalang mentah sejumlah $1000 \mathrm{~kg}$ maka ikan kayu yang diperoleh sebesar $200 \mathrm{~kg}$.

Selanjutnya bila dikaji lebih lanjut dalam proses pengolahan dengan cara sederhana ini, harus membayar tenaga kerja 2 orang @ Rp. $50.000,-=$ Rp. 100.000,-Selanjutnya ikan hasil olahan ini dibawa ke pembeli yang berada di KSU Masyarakat Pesisir dengan transportasi sebesar Rp. 100.000,-. Sehingga total biaya yang dikeluarkan sebesar Rp. 1.920.000,. Sehingga dengan jumlah produksi $200 \mathrm{~kg}$ ikan cakalang mentah menjadi $40 \mathrm{~kg}$ ikan kayu, berarti hasil penjualan $40 \times$ Rp. 90.000,- = Rp. 3.600.000,-. Ada nilai tambah sebesar Rp. 3.600.000,- - Rp. 1.920.000,- pengolah bisa mendapat untung $=\mathrm{Rp} .1 .680 .000$,sehingga dalam 4 kali produksi dalam sebulan sebesar Rp. 6.720.000,-.

\section{Hambatan-Hambatan Pada Rantai Nilai Produk Ikan Olahan}


Hambatan dalam menjalankan aktivitas pengolahan antara lain sebagai berikut :

1. Nelayan seringkali mendapat kesulitan di saat musim pancaroba.

2. Pedagang Pengumpul merasakan bahwa Tempat Pelelangan Ikan Aertembaga sudah tidak berfungsi sebagaimana mestinya.

3. Pengolah ikan kayu merasa sulitnya mendapat bahan baku yaitu berupa ikan mentah, sehingga mereka kadang-kadang tidak berproduksi atau produksi hanya dalam jumlah kecil. Rendahnya produksi akan mengakibatkan rendahnya pendapatan bahkan tidak ada sama sekali. Begitu pula dengan peralatan yang masih tradisional sehingga tidak ada pengembangan produksi. Pembeli yang hanya satu saja, menyebabkan pengolah tidak menguasai posisi tawar.

4. KSU Masyarakat Pesisir merasa masih kurang produk ikan kayu, padahal permintaan pembeli sangat besar.

\section{KESIMPULAN DAN SARAN \\ Kesimpulan}

1. Kondisi rantai nilai produk olahan Tuna Cakalang di Pulau Lembeh untuk pemasaran lokal di Kota Bitung Provinsi Sulawesi Utara.

a. Rantai nilai yang ada mulai dari pedagang pengumpul terus ke pengolah ikan dilanjutkan dengan pemasaran ke KSU masyarakat pesisir di pasar Sagrat Bitung.

b. Pada tingkat pengumpul ikan dijual dalam bentuk segar dikemas dalam keranjang atau ember/loyang besar. Dijual dengan harga Rp. 8.500,- per kg, sehingga kebutuhan rata-rata
$200 \mathrm{~kg}$ per produksi, maka pedagang pengumpul memperoleh hasil penjualan sebesar Rp. 1.700.000,--

c. Pada tingkat pengolah, ikan diproses lagi menjadi ikan olahan yaitu ikan kayu sebanyak $40 \mathrm{~kg}$ dan dijual lagi dengan harga total Rp. 3.600.000,-, biaya sebesar Rp. 220.000,- sehingga memperoleh margin atau nilai tambah sebesar Rp. 1.680.000,per produksi.

d. Di tingkat pembeli dalam hal ini KSU Masyarakat Pesisir memperoleh margin sebesar Rp. 1.550.000,--.

2. Hambatan-hambatan dalam proses pengolahan dan pemasaran produk olahan tuna cakalang di Pulau Lembeh untuk pemasaran lokal di Kota Bitung Provinsi Sulawesi Utara hanyalah pada :

a. Masih berorientasi ke pembeli yang hanya satu orang saja.

b. Memerlukan peralatan yang lebih modern untuk mendapatkan hasil produksi yang lebih tinggi.

c. Memerlukan tambahan modal, agar bisa diversivikasi hasil usaha.

\section{Saran}

Bertolak dari hambatan, maka dapatlah disarankan sebagai berikut :

1. Baik nelayan, pedagang pengumpul, pengolah ikan bisa meningkatkan produksinya melalui peralatan tangkap yang lebih baik dan lebih modern

2. Pembeli dalam hal ini KSU Masyarakat Pesisir bisa mengadakan tambahan binaan pengolah ikan sebagai penyedia ikan kayu. 


\section{DAFTAR PUSTAKA}

Anwar, A. K. 2011. Penyuluh Perikanan Tenaga Kontrak. (PPTK) IV. (Online). Available at :http://poetragor.blogspot.com/2011/03/penyulu h perikanan tenaga-kontrak-pptk_1685.html. Diakses : 18 April 2017.

Darenoh, M. 2015. Sejarah Kelurahan Batulubang di Pulau Lembeh. Https://Ejournal. Unsrat.Ac.Id/Index.Php/Jefs/Article/Viewfile/955 6/9136. Diakses Tanggal 22 Mei 2017.

Hamdi, Asep Saepul, and E. Bahruddin. 2014, Metode Penelitian Kuantitatif Aplikasi Dalam Pendidikan Yogyakarta: Deepublish, 2014.

Kotler, Philip dan Kevin Lane Keller, 2008. Manajemen Pemasaran, Jilid 1,. Penerbit Erlangga. Jakarta. Kaplan, Robert S. dan David
P. Norton, (2000), "Balanced Scorecard: Menerapkan strategi menjadi aksi",

Salim, A. 2006. Teori dan Paradigma Penelitian Sosial. Yogyakarta: Tiarawacana.

Utomo, B.S.B dan F.R. Dewi. 2010. Kondisi dan Permasalahan Industri Pengolahan Cakalang di Bitung (Kasus Pengembangan Unit Pengolahan Ikan di Bitung). Laporan Hasil Penelitian. BBRPPBKP. Jakarta.

Umar, H. 2000, "Metode Penelitian Untuk Skripsi dan Tesis Bisnis", Jakarta, Raja Grafindo Persada.

Wijaya, T. 2015. Manajemen Strategi. http://mgtstrategi.blogspot.co.id/ 2010/04/rantai-nilai-value-chain- porter. html. Diakses Juni 2017. 